\title{
Fuzzy Implication in the Area of Policy and Policy Making; a Short Non- Mathematical Introduction for Policy Makers
}

\author{
Adel Azar, PhD, Professor (Corresponding Author) \\ Department of Management and Economics \\ Tarbiat Modarres University, Tahran Iran \\ Email: azara@modares.ac.ir \\ Mohammad Reza Noruzi, EMBA, PhD Student \\ Policy Making in Public Sector \\ Tarbiat Modares University, Tehran, Iran \\ Tell: +98- 412-7238894, Fax: +98-412-7238893 \\ Email:mr.noruzi@modares.ac.ir,mr_norouzi@pnu.ac.ir,mr.noruzi.pnu@gmail.com
}

Received: July 10, 2011 Accepted: August 01, 2011 DOI: 10.5296/jpag.v1i2.804

\begin{abstract}
Between selecting and not selecting policy, there are other selections. The history of Fuzzy logic and fuzzy method do not go very beyond. But the implementation of fuzzy and its logic in different disciplines are getting increased. This paper aims to study the notion of fuzzy and policy and importance of fuzzy in today's chaotic environment for policy makers in national and international era. Also there are a lot of books and papers published on the methods on fuzzy but this paper is somehow different with them because has non-mathematical look on fuzzy and it just makes familiar the policy makers with the notion of non-mathematical fuzzy.
\end{abstract}

Keywords: Fuzzy, policy, Implications, fuzzy policy makers 


\section{Introduction}

In this area of rapid changing the style of thinking has been changed. Traditionally the thinking method was one dimensional but it has been transferred from one to two, three, four, five and sometimes too many and has been structured a multi facial thinking and method. And this has been the cause of creating creative insights to cope with the facts.

Evidence suggesting that policy and policy making is one of the fundamental parts of any government. And there are different types of policy making process in different countries, for example some countries having democratic and some have dictatorship policy making process (Danaee Fard \& Noruzi, 2011).

In the other hand, policy and policy making has been developed from the very local and initial one to the very high level ones. Previously in the very past countries had just set the very local and mainly the village level policies and then it has been changed to urban and then to country level policies so the need for selecting precise policies that look multidimensional is compulsory.

Policies are operating rules that can be referred to as a way to maintain order, security, consistency, or otherwise force a goal or mission. For example, a town council might have a policy against hiring the relatives of council members for civic positions. Each time that situation arises; council members can refer to the policy, rather than having to make decisions on a case-by-case basis (policy-based management, 2011; Noruzi \& Irani, 2011, p. 41).

Due to the increasing competition of globalization and fast technological improvements, world markets demand companies to have quality and professional human resources. This can only be achieved by choosing and selecting potentially adequate policies in the levels of national and international area. The fuzzy is as the analytical tool that determines the weights of each criterion. Fuzzy theory provides a proper tool to encounter with uncertainties and complex environment (Fathi et al, 2011).

This paper first discusses the stagiest approach for Policy Making and problem solving cycle and then studies the meaning of policy and the steps for training Fuzzy thinking policy makers at the end some related issues come as well.

\section{The stagiest approach for Policy Making and problem solving cycle}

One of the most important factors that help countries to be more developed and to be surviving in today's turbulent markets and environments is policy. Policy is as a fundamental part of any mid-term or long term planning.

Policy is applicable in all level organizations, small, middle and big some people think that policy is just needed for big organizations or companies

But it is not true in real because it is needed and necessary for all ones. We should not that a program which we plan in our own family as an economic can be considered as a policy.

All who are engaged in the process of policy no different in public policy making or the private one know that policy making process in somehow likes a problem solving process i.e. 
1. Finding a problem

2. statement of the problem

3. brainstorming for finding solution

4. analyzing the solution

5. choosing the appropriate one

And the one standardized version for policy making cycle includes the following stages:

1. Agenda setting (Problem identification)

2. Policy Formulation

3. Adoption

4. Implementation

5. Evaluation

They consider a broader range of actors involved in the policy space that includes civil society organizations, the media, intellectuals, think tanks or policy research institutes, corporations, lobbyists, etc (Medvetz, 2004).

\section{The meaning of policy}

According to the Business Dictionary (2007) about meaning of policy in politics, and management it stresses on the following issues:

- A policy prudence wisdom in the management of affairs based on primarily on priority interests

- A definite course or method of action selected from among alternatives and in light of given conditions to guide and determine present and future decisions or a high-level overall plan embracing the general goals and acceptable procedures especially of a governmental body

- A policy causes policy Learning lessons - learns from experience of what works and what doesn’t worked in the field of the study or interest (Noruzi \&, Hernandez 2010).

\section{Fuzzy decision typology}

There is a general view on decision making that it is highly related with information i.e. the amount of information will determine the decision making. The decision table (DT) below consists of a set of mutually exclusive conditions, and refer to a particular actions. Each DT consists of four quadrants:

1. Condition set, if the decision maker or policy maker have the s the condition set consists of all the relevant conditions or attributes (inputs, premises or causes) that have an influence on the decision-making process. 
2. Action set, The condition space specifies all possible combinations of condition states of a condition

3. Condition space, the action set contains all the possible actions (outputs, conclusions or consequences) a decision-maker is able to take. This is, the action set points to the possible choice outcome if (for instance) an existing location with a number of specific characteristics is processed through the DT

4. Action space, the action space contains the categorizations of all the possible action states of an action. Any vertical linking of an element from the condition space with an element from the action space produces a decision rule (Wiltox, 2005, p.2) (Figure 1).

Figure 1: The general structure of a decision table

\begin{tabular}{|l|l|}
\hline \multicolumn{2}{|l|}{ Encountered Problem } \\
\hline CONDITION SET & CONDITION SPACE \\
\hline ACTION SET & ACTION SPACE \\
\hline
\end{tabular}

Traditionally, decision is crisp, indicating that the conditions are specified in an exact manner. A potential problem of such DTs is that any measurement error is not taken into account. Fuzzy decision tables (FDTs) offer a solution to this problem. A fuzzy decision table (FDT) is an extended version of a crisp DT in order to deal with imprecise and vague decision situations (Francioni and Kandel, 1988; Vanthienen et al., 1996).

Suppose we have a set of alternatives such as a set of cities which might be destinations for some future travel plans. Let the set of four decision alternatives be denoted by;

$\mathrm{X}=\{\mathrm{x} 1, \mathrm{x} 2, \mathrm{x} 3, \mathrm{x} 4\}=\{$ Philadelphia, Los Angeles, Chicago, Newark $\}$

representing our potential destination cities of choice. Note that the set $\mathrm{X}$ is a conventional or classical set of objects. We can define a fuzzy subset of the set $\mathrm{X}$, call it $\mathrm{A}$, which is characterized by a membership function $\mu \mathrm{A}(\mathrm{xi})$ associating with each $\mathrm{xi}$. $\mathrm{X}$ a number in the interval $[0,1]$ which indicates the grade of membership of xi in A. Suppose for our example $A$ is a fuzzy subset defined as:

$A=\{$ the city in $X$ is near New York $\}=\{0.6 / x 1,0.001 / x 2,0.1 / x 3,0.9 / x 4\}$

Now the A is fuzzy one (Hagan, 2005, p.2).

In fuzzy we have three different fuzzy decision making conditions as come in the following:

1. Crisp input, crisp process, crisp output like Yager method

2. Fuzzy input, crisp process, crisp output 
3. Fuzzy input, Fuzzy process, Fuzzy output like Bonison method (Azar, 2011)

The extension amounts to the introduction of fuzzy sets in the condition and action space of the crisp DT; the crisp condition and action states are replaced with fuzzy conditions and actions. (Wiltox, 2005, p.2)

\section{For training Fuzzy thinking policy makers what steps should be done?}

After world war second, several mathematical techniques were developed to determine the optimal utilization of reservoirs. Introducing sequential programming algorithm by Little in 50's and developing dynamic programming models facilitated the process of modeling for the operation of reservoirs (Loucks ant et al, 1981; Manton and et al, 1994)

The aims of designing these models were to find optimal policies for limited or unlimited time periods. Also, all methods of optimization are classified as either deterministic or stochastic (Azar and et al, 2002, p.27).

Noble purpose of discussing the progress of research on fuzzy and policy is an important step to stimulate the debate on fuzzy policy makers. As we have mentioned fuzzy policy makers think differently with domestic ones and in this era, the era of rapid changing we need fuzzy ones. Following steps will help to training fuzzy policy makers:

- Holding some workshops on fuzzy policy making process in all areas in the country including policies for health, housing, income maintenance, education and social work;

- Creation of theoretical and methodological models for analysis and communication for fuzzy policy makers related results in projects

- Dissemination of key findings in the context of the fuzzy policy making today.

- Trying to use logic of fuzzy in the management sphere

- Holding some classes in the universities and colleges for the students who want to be fuzzy policy makers in the future

- Adding some university units for the university students for policy making in fuzzy to learn fuzzy policy making beside the domestic one.

- Using from fuzzy policy makers in different countries who have successful experiences regarding the fuzzy policy making establishment.

- Learning fuzzy policy making strategies

- Try to use fuzzy knowledge and fuzzy logic in policy making learners

- Fuzzy Policy talk shows in the TV channels regarding the process and the advantages of this system.

- Clarifying country's policy in some specific disciplines

- Clarifying why fuzzy policy is important and the advantages and the disadvantages of 
it

- Doing comparative studies on the differences of domestic and fuzzy policy making

- Monitoring the policy which has been implemented by fuzzy insight

- Implementing the pilot fuzzy policy making

- Needs and issues affecting the users of fuzzy services (Spicker, 2007 Noruzi \& Irani, 2011).

\section{The importance of Fuzzy thinking in the organizational efficacy}

Fuzzy thinking will help the community much more improvement in different aspects for example some come in the following:

- Quality of decision will be increased

- $\quad$ Thinking and the policy will be analyzed from multi faces

- The promotions will be precise

- The evaluations will be precise, because managers and policy makers in the organizations and those who are engaged in selecting people will be evaluate exactly.

- Organizational attitude will be change because staff will not label the others just bad or good

- Economic decisions will be improved by considering fuzzy logic.

\section{Policy Contents in Fuzzy system}

A policy always has different contents but mainly there are some similarities among them below also there are some differences among the non fuzzy policy contents and the fuzzy policy contents. And policy makers should pay much more attention to this important we bring the common ones in the following

- Introducing the fuzzy logic for the audience in the meeting

- A purpose statement in fuzzy i.e. it should be not in binaries method just yes or no Policy statements are extremely diverse depending on the organization and intent, and may take almost any form.

- An applicability and scope of a policy this mean that we analyze that can this policy applicable or not in the fuzzy system or in non fuzzy as well.

- An effective date gathering

- An effective using from the gathered data in fuzzy method and transferred it to the fuzzy sphere.

- $\quad$ Responsibilities of applying the fuzzy system (Vargas Hernandez \& Noruzi, 2011). 


\section{Results and discussions}

In this age of increased competitive environment and management, the notion of the decision making and policy making and policy choosing are getting problems have an enormous interest. Policy makers and international and national decision makers face rising and complex environments today, and also decision makers are often uncertain in assigning the evaluation scores in crisp value.

Fuzzy Policy making is a multidisciplinary and subject area, not a discipline; it borrows from other natural and basic and social science disciplines in order to develop study in the area. The contributory disciplines include mathematics, social work, statistics, economics, political science, management, history, philosophy and law (Spicker, 2007).

Therefore, in this paper, we have studied policy notion based on fuzzy theory to select the most adequate policy. Unlike other decision methods, the fuzzy can adaptively find a suitable policy for the country or the place where policy wants to be implemented (Fathi et al, 2011).

Policy is the study of services and the welfare. In general terms, it looks at the idea of social welfare, country's issues and its relationship to politics and society.

Applying fuzzy in the policy making area is distinct as an academic field which focuses on the systematic evaluation of responses to the needs. For example in Iran some pioneer universities have a specific university courses and studies on policy and policy making universities like Tarbiat Modarres University is as an example of this pioneer university who has a good background on this studying (Rittel \& Webber, 1973).

Modern governments should try to use fuzzy implications in all levels of the country if there be based on a social contract between scholars and the state in which rights and duties are agreed to by all to further the common interest. Scholars in different related sciences to fuzzy logic lend their support to a government through new and updated information to a country's governments acquire legitimacy by protecting the people's rights and through public policies that benefit all (Ortiz, 2007, p. 7).

Regarding the importance of fuzzy policy, and fuzzy policy making, it is better to say that; Policy is very important for us and we should note for this important that policy causes different goals be more integrated and this integrations causes government' success some integration causes come as the following:

- translate values into operations;

- $\quad$ ensure compliance with legal and statutory responsibilities;

- guide the University towards the achievement of its strategic plan;

- $\quad$ set standards; and

- Improve the management of risk (policy library, 2011).

Countries which do not from systematic policy making processes they will not be more success. They do not really know where they want to go. Policy is just like a bulb in the dark 
it is lightened the way the country wants to go. Also policy helps country in designing the long term planning although very long term policies today are not possible because of the very fast environmental changes but this not means omitting the policy making.

Understanding this important will help governors to make good and appropriate decisions and manage the situations well.

At the end we can conclude that binary and noncontiguous perspective causes to choose just yes or no but in this area we know that between the numbers of zero and one there are a lot of numbers to be chosen i.e. in policy between selecting and not selecting policy there are other selections. Using the fuzzy in the area that can be applied will show a high jump in the result and the attitude of both the employee and boss because in the non fuzzy area we can say just good or bad for an employee but we can say the fuzzy statements in the fuzzy area. Hope this can open new perspectives in other areas of management.

\section{References}

Azar Adel Mehran Hosseiny Farazmand Ali Asghar Anvary Rostamy, (2002) FUZZY PARTITIONING AND ITS APPLICATION TO RESERVOIR OPERATION PROBLEM (A MULTISTAGE APPROACH USING MARKOV CHAIN), Journal of the Operations Research Society of Japan Vol. 45, No. 1, March 2002 pp. 27-35

Azar, Adel, (2011), Multivariate and fuzzy statistical course, unpublished class note in doctoral program for policy making students, Tarbiat Modarres University, second semester

Business Dictionary, (2007), available online at: Http: // www.business dictionary.com

Danaee Fard, Hassan- Mohammad Rea Noruzi, (2011), Policy and Policy making in Iran: Issues and process, 6th edition of the International Conference on European Integration Realities and Perspectives ，Galati, Romania, on May 13th - 14th, 2011.

Fathi, Mohammad Reza, Hassan Zarei Matin, Mohammad Karimi Zarchi, Sirous Azizollahi, (2011), The Application of Fuzzy TOPSIS Approach to Personnel Selection for Padir Company, Iran, Journal of Management Research, 2011, Vol. 3, No. 2: E15 ,pp 1-14

FRANCIONI, J.M. \& A. KANDEL (1988) “A software engineering tool for expert system design”. IEEE Expert. Vol. 3 (1), pp. 33-41.

Hagan, O'Hagan, (2005), A FUZZY DECISION MAKER, available at: http://www.google.com/url?sa=t\&source=web\&cd=1\&ved=0CBoQFjAA\&url=http\%3A\%2F \%2Fciteseerx.ist.psu.edu\%2Fviewdoc\%2Fdownload\%3Fdoi\%3D10.1.1.94.7068\%26rep\%3D rep1\%26type\%3Dpdf\&rct=j\&q=A\%20FUZZY\%20DECISION\%20MAKER\&ei=VIYWTpa BBcWGsALdg6B2\&usg=AFQjCNEKXk_7yc1zJogxp9Evw0zApVKNng\&sig2=xTg-iRTDz RykSx5W4A3IGw\&cad=rja

Hernández, José G. Vargas-, Mohammad Reza Noruzi, Farhad Nezhad Haj Ali Irani,(2011) What is Policy, Social Policy and Social Policy Changing, International Journal of Business and Social Science Vol. 2 No. 10; June 2011, pp.287-291 
Kilpatrick, Dean G. (2000), Definitions of Public Policy and the Law, National Violence Against Women Prevention Research Center

Loucks, D.P., J.R. Stedinger and D.A. Haith: (2005), Water Resource Systems Planning and

Manton, K.G., M.A. Woodbury and H.D. Tolley: (2005), Statistical Applications Using Fuzzy

Medvetz ,Tom (2004) on the definition of think tanks within a social space: on the definition of think tanks, onthinktanks

Noruzi, Mohammad Reza, Farhad Nezhad Haji Ali Irani, (2011), POLICY AND SOCIAL POLICY: MEANINGS AND IMPICATIONS IN SOCIETY, Business and Management Review Vol. 1(3) pp. 41 - 46, May, 2011

Noruzi, Mohammad Reza, Jose G Vargas Hernandez, (2010), A Short Note on the Effective Policy Making Strategies in the Public Sector Organizations. Interdisciplinary journal of contemporary research in business, August, Vol. 2. No. 4 (2010). pp. 382-387.

Ortiz, Isabel, (2007), Social Policy, NATIONAL DEVELOPMENT STRATEGIES POLICY NOTES, UNITED NATIONS DEPARTMENT FOR ECONOMIC AND SOCIAL AFFAIRS (UNDESA)

Policy based- management, (2011), what is .com available on line at: http://whatis.techtarget.com/definition/0,,sid9_gci537241,00.html

Policy library, (2011), what is policy making role available online at: http://www.newcastle.edu.au/service/policy/definition.html

Rittel, H. \& Webber, M. (1973). Dilemmas in a General Theory of Planning. Policy Sci 4:155-169. Sets (John Wiley and Sons Inc, 1994).

Social Policy, (2006), available at : http://en.wikipedia.org/wiki/Social_policy

Spicker, Paul, (2007), an introduction to Social Policy, Social Policy, available online at: http://www2.rgu.ac.uk/publicpolicy/introduction/index.htm

Strategic Policy Making Team Cabinet Office (1999), Professional Policy Making for the Twenty First Century

VANTHIENEN, J., G. WETS \& G. CHEN (1996) "Incorporating fuzziness in the classical decision table formalism”. International Journal of Intelligent Systems, Vol. 11 (11), pp. 879-891.

Webster Merriam dictionary (2005), available on line at: http://www.merriam-webster.com/dictionary/policy

Wikipedia, (2011), policy available at: http://en.wikipedia.org/wiki/Policy

WITLOX Frank J.A., Aloys W.J. BORGERS, Harry J.P. TIMMERMANS, (2005), MODELLING LOCATIONAL DECISION MAKING OF FIRMS USING MULTIDIMENSIONAL FUZZY DECISION TABLES: AN ILLUSTRATION 


\section{Macrothink

Young, John and Enrique Mendizabal (2009). Helping researchers become policy entrepreneurs, Overseas Development Institute 